\title{
Effects of exogenous insulin on placental transfer of maternal glucose to the rat fetus
}

\author{
X. Testar ${ }^{1}$, M. A. Lasunción ${ }^{2,3}$ R. Chieri ${ }^{1}$ and E. Herrera ${ }^{2,3}$ \\ ${ }^{1}$ Cátedra de Fisiologia General, Universidad de Barcelona and 2Departamento de Investigación, Centro Especial "Ramón y Cajal”, Madrid, \\ and 3 Departamento de Bioquimica, Facultad de Medicina, Universidad de Alcalá de Henares, Madrid, Spain
}

\begin{abstract}
Summary. There is controversy concerning the possible modulation of glucose transfer to the fetus by insulin acting on the maternal side of the placenta. To study this question, 20.5 day pregnant rats were infused simultaneously with $\left(\mathrm{U}^{1}{ }^{14} \mathrm{C}\right)-\mathrm{D}$ glucose (via the jugular vein) and with different doses of insulin (via the left uterine artery) so that placentas from the left uterine horn were exposed to a higher insulin concentration than those from the right uterine horn. Placentas and fetuses from each uterine side were processed separately. No differences were detected in total blood radioactivity, plasma $-{ }^{14} \mathrm{C}$ glucose, ${ }^{14}$-C-lactate, -glucose, or -radioimmunoassayable insulin in fetuses from the left versus the right uterine horn. Total placenta radioactivity and ${ }^{14} \mathrm{C}$-glycogen were also similar
\end{abstract}

in the left and right uterine sides at all insulin doses studied. Infusion of insulin $(66 \mathrm{mU} / \mathrm{min})$ to the pregnant rat caused hyperinsulinaemia and hypoglycaemia, decreased blood total radioactivity and plasma ${ }^{14} \mathrm{C}$-glucose, and increased plasma ${ }^{14} \mathrm{C}$-lactate in the mother. The level of fetal plasma ${ }^{14} \mathrm{C}$-glucose paralleled that of the mother. It is concluded that in the rat, placental glucose uptake, its transfer to the fetus, and fetal glucose utilization are not directly affected by maternal circulating insulin. Metabolic changes occurring in fetuses of hyperinsulinaemic mothers are secondary to the decreased availability of glucose.

Key words: Placenta, glucose transfer, insulin, rat fetus.
Maternal glucose is a basic fuel for fetal oxidative metabolism [1, 2]. Fetal circulating glucose parallels alterations in maternal glycaemia [3, 4] because glucose transfer across the placenta takes place by facilitated diffusion $[5,6]$ which depends on maternal glucose concentration [7]. Infusion of insulin into the sheep fetus reportedly increases fetal glucose utilization and its uptake from the mother [8] and similar results have been found in the rat [9]. Since the placenta is known to contain insulin receptors [10-13] and maternal hyperinsulinaemia occurs during late pregnancy $[14,15]$, the question has been raised whether maternal insulin acting on the placenta could stimulate glucose transfer to the fetus. The effects of insulin on the placenta have been investigated in human [16-20] and in ruminant preparations [21-24] yielding both positive [16, 17, 19, 22, 23] and negative $[18,20,21,24]$ results. No studies have been performed on insulin effects on the rat placenta which contains a much lower number of insulin receptors than the placentas of other species [10]. Changes in insulin levels in maternal circulation have been reported to affect fetal/maternal glucose relationships in the rat [25-27]. We therefore studied whether rat placenta glucose transfer is sensitive to increments in maternal insulin levels. For this purpose we infused exogenous insulin via the left uterine artery, according to our recently described technique [28], simultaneously with an infusion of $\left(\mathrm{U}-{ }^{14} \mathrm{C}\right)-\mathrm{D}$-glucose via the jugular vein. The effect of insulin was determined by comparing the ${ }^{14} \mathrm{C}$ variables in fetuses from the left and right uterine horns.

\section{Materials and methods}

\section{Animals and surgical procedure}

Fed pregnant Wistar rats at day 20.5 of gestation (determined by the appearance of spermatozoids in vaginal smears), weighing $270-290 \mathrm{~g}$, were anaesthetized intravenously with sodium pentobarbital (33 mg' $\mathrm{kg}$ body weight). After laparatomy, a cannula (PE-10, Intramedic, Clay Adams, NY, USA) was introduced into the left external iliac artery to the beginning of the superior vesical artery which was clamped distally to the left uterine artery exit level (Fig. 1, cannula 1). The infusion medium, introduced through the cannula by means of a peristaltic pump, therefore combined with blood circulating through the left uterine artery. Other details of the surgical procedure were as previously described [28]. The rats were also infused through a cannula (PE-50, Intramedic, Clay Adams, NY, USA) placed in the jugular vein (Fig. 1, cannula 2). 


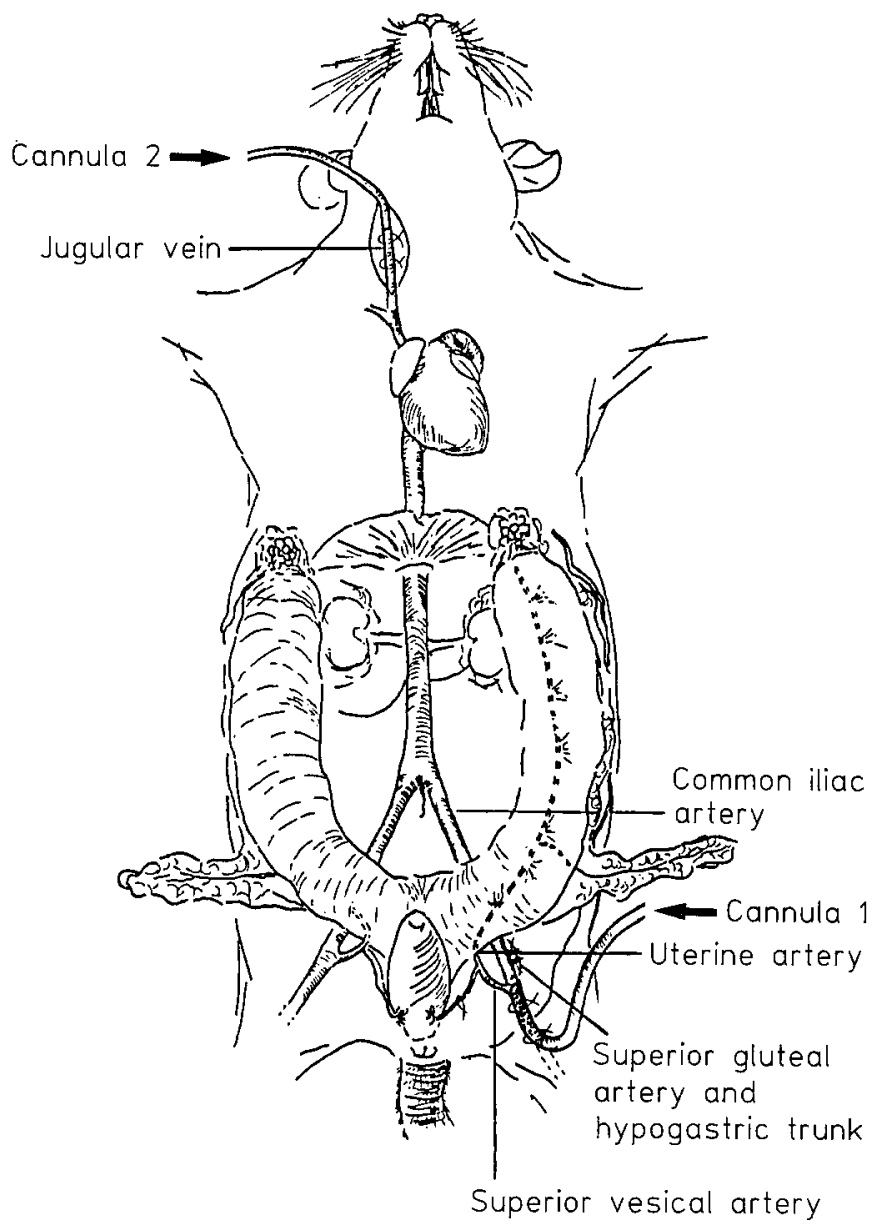

Fig. 1. Scheme of our experimental procedure showing location of the infusion cannulas. Media containing either insulin or saline was introduced via cannula 1 , and media containing $\left(\mathrm{U}-{ }^{14} \mathrm{C}\right)$-D-glucose was introduced via cannula 2

\section{Experiments with $\left(U-{ }^{14} C\right)$-D-glucose}

Rats were infused simultaneously with a solution of $20 \mathrm{UCi} \cdot \mathrm{ml}^{-1}$ of $\left(\mathrm{U}^{14} \mathrm{C}\right)$-D-glucose (specific activity 199.6 Ci $\cdot \mathrm{mol}^{-1}$, Amersham International, Amersham, Bucks, UK) via the jugular vein (Fig. 1, cannula 2) at a rate of $20 \mu \mathrm{l} \cdot \mathrm{min}^{-1}$ and with a solution of pork monocomponent insulin (Actrapid, Novo Industri, Copenhagen, Denmark) $\left(20 \mu \mathrm{l} \cdot 0.66 \mathrm{mU}^{-1} \cdot \mathrm{min}^{-1}\right.$ or $20 \mu \mathrm{l} \cdot 66$ $\mathrm{mU}^{-1} \cdot \mathrm{min}^{-1}$ ). In a control group of rats $0.9 \% \mathrm{NaCl}$ $\left(20 \mu \mathrm{l} \cdot \mathrm{min}^{-1}\right)$ was infused via the left uterine artery (Fig. 1, cannula 1). Eight to eleven rats were studied in each experimental group. After $15 \mathrm{~min}$ of infusion, 3-4 $\mathrm{ml}$ of blood were collected from the aorta into heparinized syringes and the fetuses and placentas from both uterine sides were excised. Livers from the mothers and from some fetuses, as well as the placentas, and one whole fetus from each uterine horn were placed immediately in liquid $\mathrm{N}_{2}$. Aliquots of blood $(25 \mu \mathrm{l})$ were decoloured with hydrogen peroxide for counting total radioactivity. Plasma from other blood aliquots was used for measurement of insulin [29] with a radioimmunoassay kit for rat insulin (generously provided by Novo), and for deproteinization with $\mathrm{Ba}(\mathrm{OH})_{2}-\mathrm{ZnSO}_{4}[30]$.
When separation of ${ }^{14} \mathrm{C}$-glucose and ${ }^{14} \mathrm{C}$-lactate was required, 100-200 $\mu 1$ plasma aliquots were deproteinized with $10 \% \mathrm{HClO}_{4}$, and $\mathrm{KHCO}_{3}$-neutralized supernatants were used for both glucose measurement [31] and subjected to ascending chromatography on Whatman 3MM paper in n-butanol-water-methanol-formic acid (320:320:81:1, by volume) [32]. Spots were identified using purified standards run in parallel and spots were directly used for counting their radioactivity. Frozen livers, placentas, and whole fetuses were pounded in a porcelain mortar under liquid $\mathrm{N}_{2}$ and weighed aliquots (approximately $0.5 \mathrm{mg}$ ) were used for digestion in $2 \mathrm{ml}$ of $30 \% \mathrm{KOH}$ in a boiling water bath for $10 \mathrm{~min}$. Glycogen was precipitated three times with ethanol in the cold [33]. Glycogen precipitates were hydrolized with $5 \mathrm{~N} \mathrm{H}_{2} \mathrm{SO}_{4}$ at $100^{\circ} \mathrm{C}$ for $2 \mathrm{~h}$ and after neutralization with $\mathrm{NaOH}$, aliquots were used for determination of glucose with glucose-oxidase [31]. This procedure has previously been validated by us [14].

${ }^{14} \mathrm{C}$-radioactivity measurements were performed in a scintillation mixture containing $750 \mathrm{ml}$ of xylene, $250 \mathrm{ml}$ of triton-X-100, $3 \mathrm{~g}$ of PPO and $100 \mathrm{mg}$ of POP$\mathrm{OP}$, and results were corrected by considering $1 \times 10^{6} \mathrm{dpm}$ as the total infused radioactivity per rat.

\section{Statistical analysis}

Statistical comparisons between the groups were performed with the Student's paired and unpaired t-test.

\section{Results}

\section{Plasma insulin, glucose, and liver glycogen}

Rats at 20.5 days of gestation were infused simultaneously for $15 \mathrm{~min}$ with saline or insulin via the left uterine artery (Fig. 1, cannula 1) and $\left(\mathrm{U}^{-14} \mathrm{C}\right)$-D-glucose via the jugular vein (Fig. 1, cannula 2). Insulin increased plasma radioimmunoassayable-insulin and decreased plasma glucose levels in the infused mother, although this effect was significant only when insulin was administered at the rate of $66 \mathrm{mU}$ per min. Maternal insulin infusion via the left uterine artery did not modify either plasma insulin or glucose levels in fetuses from both left and right uterine horns (Table 1). In basal conditions, during maternal saline infusion, plasma fetal insulin levels were slightly higher than in their mothers $(p<$ 0.05 ) whereas after maternal infusion with $66 \mathrm{mU}$ per min of insulin plasma fetal insulin levels became significantly and similarly reduced in both the left and right uterine horns (Table 1). Fetal plasma glucose levels were lower than maternal levels after saline infusion $(p<0.001)$, but this difference disappeared after maternal insulin infusion (Table 1). Liver glycogen concentration did not differ in fetuses from the left and right uterine horns in any of the experimental groups studied (Table 1) and values were always much higher in fetuses 
Table 1. Plasma insulin, glucose, and liver glycogen concentrations in 20.5-day-pregnant rats and their fetuses after infusion of either saline or insulin, via the left uterine artery and $\left(\mathrm{U}-{ }^{14} \mathrm{C}\right)$-D-glucose via the jugular vein

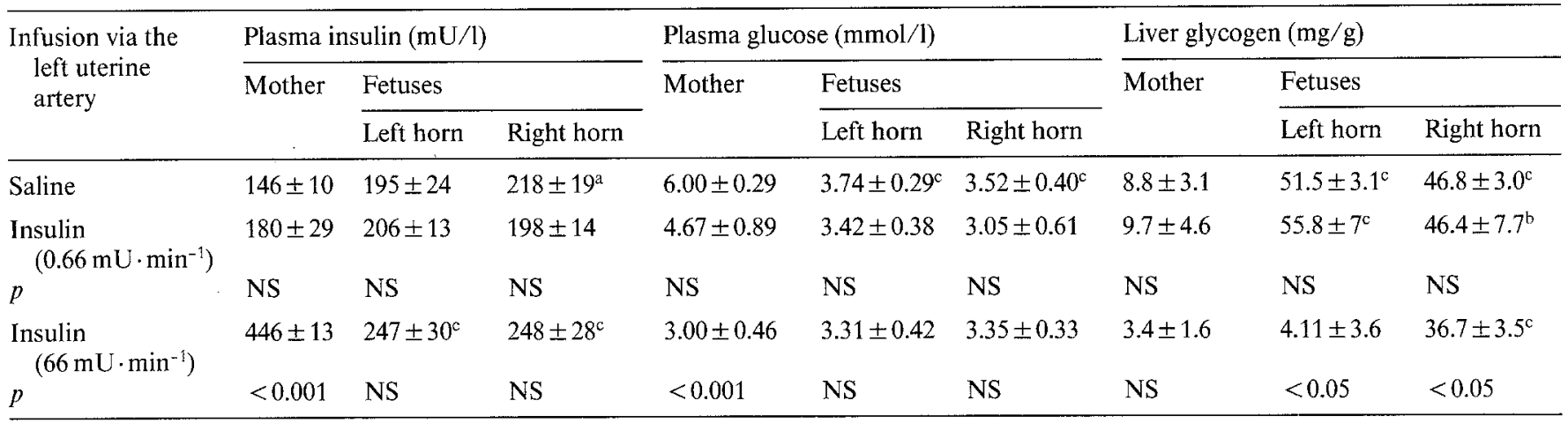

Infusions were performed for $15 \mathrm{~min}$ under pentobarbital anaesthesia. Values correspond to mean \pm SEM of $8-11$ rats/group. Statistical comparisons for each insulin-treated group versus the saline control group are indicated by the $p$ values whereas those for fetuses versus mothers are indicated by "a" $(p<0.05)$, "b" $(p<0.01)$ or " $\mathrm{c}$ " $(p<0.001)$. Comparisons between fetuses from left and right horns were not significant $(p>0.05)$ in any of the groups studied

Table 2. Total radioactivity in blood, whole fetuses and placentas, and placental ${ }^{14} \mathrm{C}$-glycogen in 20.5 -day-pregnant rats and their fetuses after the infusion of either saline or insulin via the left uterine artery and $\left(\mathrm{U}-{ }^{14} \mathrm{C}\right)$-D-glucose via the jugular vein

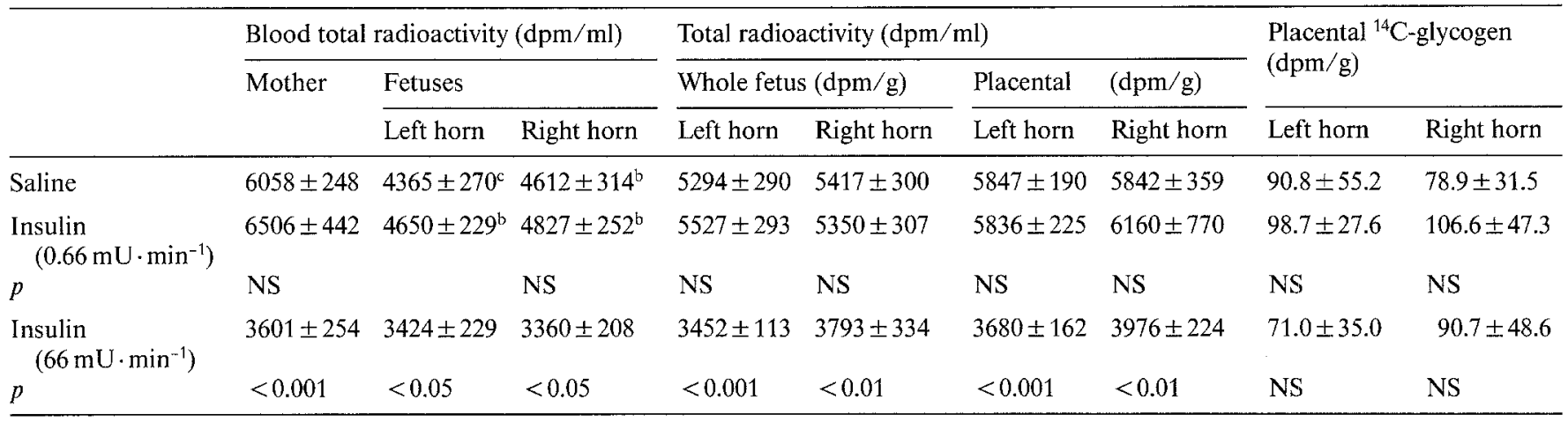

Infusions were performed for 15 min under pentobarbital anaesthesia. Values correspond to mean \pm SEM of $8-11$ rats/group. Statistical comparisons for each insulin treated group versus the saline control group are indicated by $p$ values whereas those for fetuses versus mothers are indicated by "b" $(p<0.01)$ or " $\mathrm{c}$ " $(p<0.001)$. Comparisons between fetuses from left and right horns were not significant $(p<0.05)$ in any of the groups studied

than in their respective mothers. Maternal insulin infusion decreased liver glycogen concentration in fetuses from mothers receiving the highest insulin concentration $\left(66 \mathrm{mU} \cdot \mathrm{min}^{-1}\right)(p<0.05)$.

\section{Labelled circulating metabolites}

Plasma ${ }^{14} \mathrm{C}$-glucose levels did not differ in fetuses from the left and right uterine horns in any of the groups studied (Fig. 2) and values were always lower in fetuses than in their respective mothers. In maternal plasma, ${ }^{14} \mathrm{C}$-glucose values decreased after the infusion via the left uterine artery with $66 \mathrm{mU} \cdot \mathrm{min}^{-1}$, but not with $0.66 \mathrm{mU} \cdot \mathrm{min}^{-1}$ of insulin, and this effect was paralleled in values of fetuses from both left and right horns which remained significantly below maternal levels (Fig. 2). In contrast to ${ }^{14} \mathrm{C}$-glucose, maternal plasma ${ }^{14} \mathrm{C}$-lactate increased with insulin infusion (Fig. 3). Plasma ${ }^{14} \mathrm{C}$-lactate levels were always higher in fetuses than in their mothers and values never differed in fetuses from the left versus the right uterine side, nor did maternal insulin infu- sion affect this variable in their respective fetuses (Fig. 3).

\section{Total radioactivity in blood, fetuses and placentas and placental ${ }^{14} \mathrm{C}$-glycogen}

Blood total radioactivity did not differ in fetuses from the left and right horns and fetal were lower than maternal values when mothers received either saline or the low concentration of insulin via the left uterine artery (Table 2). Both fetal and maternal total radioactivity levels in blood, however, decreased significantly when mothers received $66 \mathrm{mU} \cdot \mathrm{min}^{-1}$ insulin instead of saline (Table 2). There were no differences in the total radioactivity of placentas and fetuses from the left versus the right uterine horns (Table 2), and whereas these values were similarly unaffected by the low dose of insulin and by saline infused through the left uterine artery, the higher insulin dose used $\left(66 \mathrm{mU} \cdot \mathrm{min}^{-1}\right)$ caused a significant reduction $(p<0.01)$. This decrease was similar in placentas and fetuses from both uterine sides (Table 2) 


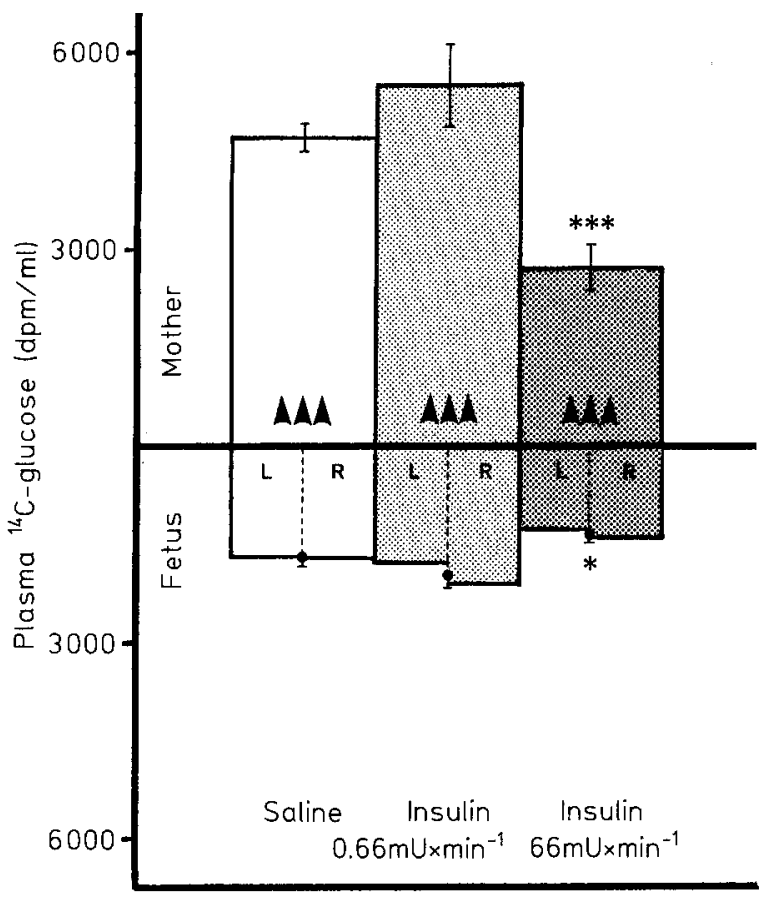

Fig. 2. Plasma ${ }^{14} \mathrm{C}$-glucose in 20.5 -day pregnant rats and their fetuses after $15 \mathrm{~min}$ infusion of either saline or insulin via the left uterine artery, and (U- ${ }^{14} \mathrm{C}$ )-D-glucose via the jugular vein. Values correspond to means $\pm S E M$ of 6 rats per group. Statistical comparisons of mean values for fetuses from the left $(\mathrm{L})$ and right $(\mathrm{R})$ uterine horns were not significant in any of the groups studied $(p>0.05)$. Statistical comparisons between mean values of all fetuses versus their respective mother are shown by $\wedge(\wedge \wedge=p<0.001)$, and values of insulin versus saline infusion for both mothers and fetuses are indicated by * $(*=p<0.05 ; * * *=p<0.001)$

and also paralleled the effect on total blood radioactivity produced by $66 \mathrm{mU}$ insulin $\cdot \mathrm{min}^{-1}$ in the mother. A small proportion of placental radioactivity correspondend to ${ }^{14} \mathrm{C}$-glycogen and maternal insulin infusion did not affect this variable in placentas from either left or right uterine horns (Table 2).

\section{Discussion}

Infusion of the late pregnant rat via the left uterine artery as described in the present study has been validated recently as a sensitive technique to detect placental Dglucose, L-alanine, and glycerol transfer mechanisms $[28,34]$. Infusion of insulin through the left uterine artery should produce a higher concentration of insulin in blood irrigating the left versus the right uterine horn. The simultaneous infusion of ${ }^{14} \mathrm{C}$-glucose through the jugular vein of the rat mother permits determination of possible direct effects of insulin on placental function by comparison of samples from the left versus the right uterine sides. The present results show that infusion for 15 min of sufficient amounts of insulin to double maternal radioimmunoassayable-insulin concentration does not alter the radioactivity values in uteroplacental struc-

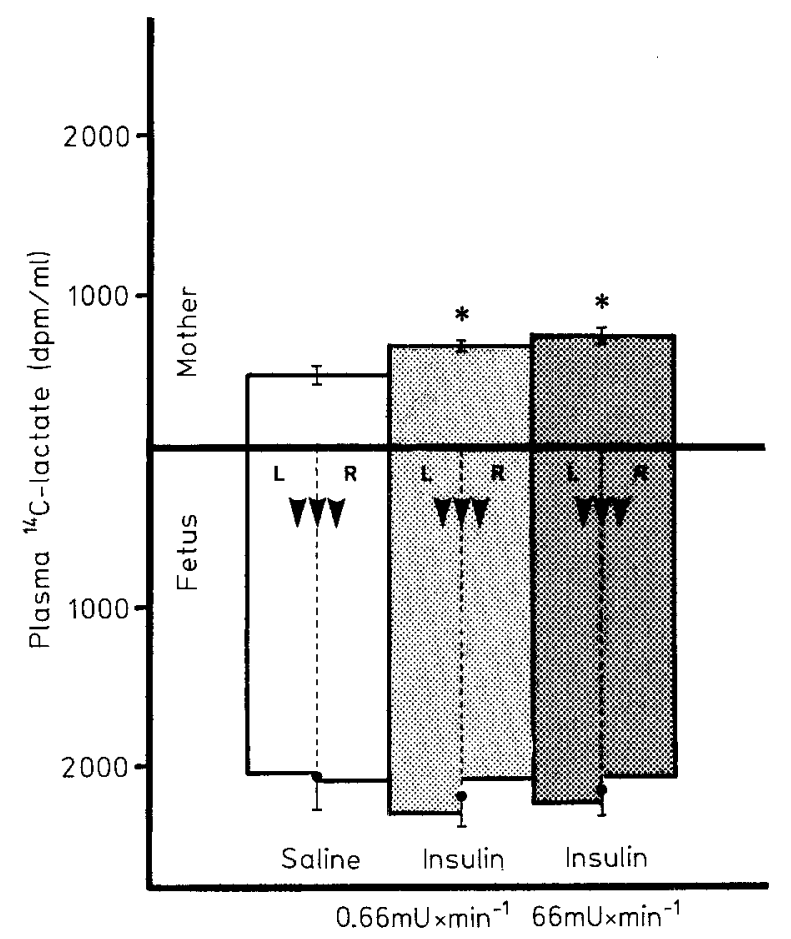

Fig. 3. Plasma ${ }^{14} \mathrm{C}$-lactate in 20.5 day pregnant rats and their fetuses after $15 \mathrm{~min}$ infusion of either saline or insulin via the left uterine artery, and (U. $\left.{ }^{14} \mathrm{C}\right)$-D-glucose via the jugular vein. Values correspond to means \pm SEM of 6 rats per group. Statistical comparisons of mean values for fetuses from the left (L) and right $(R)$ uterine horns were not significant in any of the groups studied $(p>0.05)$. Statistical comparisons between mean values of all the fetuses versus their respective mothers are indicated by $\nabla(\vee \vee \vee=p<0.001)$ and those of insulin infusion versus saline for both mothers and fetuses by $*(*=p<0.05)$

tures of the left and right uterine horns. Experiments in which infusion of insulin was prolonged up to 1 hour led to similar negative results (data not shown), indicating that this hormone does not affect glucose transfer in the rat placenta. Our conclusion differs from that of Paxon et al. [22] and Crandall et al. [23] in sheep, but is in agreement with Hay et al. [24] who, using the glucose clamp methodology, showed that variations in maternal insulin concentration in pregnant sheep did not modify placental glucose uptake or transfer to the fetus. While sheep placenta specifically binds insulin [35], this hormone does not modulate glucose uptake or utilization in in vitro preparations [21]. In the human placenta, which is rich in insulin receptors $[10,36]$, it has been reported that glucose metabolization is either sensitive $[16,19]$ or insensitive $[18,37]$ to added insulin in vitro. Similarly contrasting results have also been observed in the regulation by insulin of amino acid uptake by human placenta $[17,20]$. Placental insulin binding capacity is lower in the rat than in other mammals [10] and, to our knowledge, there is no published evidence that placental metabolism is directly influenced by maternal insulin. The present study revealed no effect on placental glucose uptake (as indicated by placental radioactivity) or on glucose incorporation into placental glycogen, 
in agreement with reports that several enzyme activities, influenced by insulin in other rat tissues, are not insulinsensitive in the placenta $[27,38]$.

These findings, together with present results showing that increased maternal insulin levels do not modify placental permeability to glucose, indicate that this hormonal change does not modify placental function and metabolism in the rat. This conclusion coincides with reports that, in severely diabetic pregnant rats, fetal blood glucose levels passively follow maternal values [39] and enzyme activities in placentas do not differ from those in controls [38]. A "permissive" role for insulin in certain placental functions cannot be totally discarded as no extreme conditions of insulin deficiency and replacement were tested in the present study.

As expected, administration of high insulin doses $\left(66 \mathrm{mU} \cdot \mathrm{min}^{-1}\right)$ to the mother decreased both glucose concentration and ${ }^{14} \mathrm{C}$-glucose levels and enhanced ${ }^{14} \mathrm{C}$ lactate values in maternal plasma. These changes were paralleled by the fetus only in ${ }^{14} \mathrm{C}$-glucose, indicating that it was affected as a secondary consequence of maternal alterations due to insulin. As indicated by the mother/fetus plasma ${ }^{14} \mathrm{C}$-glucose ratios, the plasma ${ }^{14} \mathrm{C}$ glucose mother-to-fetus gradient was of similar magnitude in both the saline- and insulin-infused rats.

The fetal plasma glucose concentration deserves special comment. Fetuses from mothers infused with saline showed plasma glucose levels predictably lower than in their respective mothers. With the insulin infusions, the decrease in maternal glycaemia was not paralleled in the fetus, and maternal and fetal glucose concentrations became similar. Comparable results have been observed in the fasted rat and after maternal insulin administration [40]. Since liver glycogen content decreased in fetuses from mothers infused with insulin $\left(66 \mathrm{mU} \cdot \mathrm{min}^{-1}\right)$, enhanced glycogenolysis probably compensates for the reduced availability of incoming maternal glucose. Fetal glucose metabolism does not seem, however, to be affected by maternal insulin infusion, as indicated by the unchanged ${ }^{14} \mathrm{C}$-lactate level in fetal plasma. Therefore we may conclude that in the rat, placental glucose uptake, its transfer to the fetus, and fetal glucose utilization are not directly affected by maternal circulating insulin. Moreover, metabolic changes occurring in fetuses of hyperinsulinaemic mothers are secondary to the decreased availability of glucose and presumably of other substrates crossing the placenta.

Acknowledgements. The present study was performed with a grant from the Comisión Asesora para Investigación Cientifica y Técnica, Ministerio de Educación y Ciencia of Spain. The authors wish to thank C.S. Delgado for her editorial help.

\section{References}

1. Boyd RDH, Morris FH Jr, Meschia G, Makowski EL, Battaglia FC (1973) Growth of glucose and oxygen uptakes by fetuses of fed and starved ewes. Am J Physiol 225:897-902
2. Battaglia FC, Meschia G (1978) Principal substrates of fetal metabolism. Physiol Rev 58: 499-527

3. Girard JR, Ferré P, Gilbert M, Kervran A, Assan R, Marliss EB (1977) Fetal metabolic response to maternal fasting in the rat. Am J Physiol 232: E456-E463

4. Kervran A, Randon J, Girard JR (1979) Dynamics of glucose-induced plasma insulin increase in the rat fetus at different stages of gestation. Effects of maternal hypothermia and fetal decapitation. Biol Neonate 35: 242-248

5. Widdas WF (1952) Inability of diffusion to account for placental glucose transfer in sheep and consideration of the kinetics of a possible carrier system. J Physiol 118: 23-39

6. Rice PA, Rourke JE, Nesbitt REL Jr (1979) In vitro perfusion studies of the human placenta. VI. Evidence against active glucose transport. Am J Obstet Gynecol 133: 649-655

7. Morris FH Jr (1981) Placental factors conditioning fetal nutrition and growth. Am J Clin Nutr 34: 760-768

8. Simmons MA, Jones MD Jr, Battaglia FC, Meschia G (1978) Insulin effect on fetal glucose utilization. Pediatr Res 2: 90-92

9. Rabain F, Picon L (1974) Effect of insulin on the materno-fetal transfer of glucose in the rat. Horm Metab Res 6: 376-380

10. Posner BI (1974) Insulin receptors in human and animal placental tissue. Diabetes 23: 209-217

11. Durán-Garcia S, Gómez-Nieto J, Marañón-Cabello A (1979) Effect of gestational diabetes on insulin receptors in human placenta. Diabetologia 16: 87-91

12. Deal CL, Guyda HI (1984) Insulin receptors in human term placental cells and choriocarcinoma (JEG-3) cells: characteristics and regulation. Endocrinology 112: 1512-1523

13. Machicao F, Urumow T, Wieland OH (1982) Phosphorylation-dephosphorylation of purified insulin receptor from human placenta. Effect of insulin. FEBS Lett 49: 96-100

14. Herrera E, Knopp RH, Freinkel N (1969) Carbohydrate metabolism in pregnancy. VI. Plasma fuels, insulin, liver composition, gluconeogenesis, and nitrogen metabolism during late gestation in the fed and fasted rat. J Clin Invest 48: $2260-2272$

15. Saudek CD, Finkowski M, Knopp RH (1975) Plasma glucagon and insulin in rat pregnancy. Roles in glucose homeostasis. J Clin Invest 55: 180-187

16. Villee CA (1953) The metabolism of human placenta in vitro. $J$ Biol Chem 205: 113-123

17. Dancis J, Money WL, Springer D, Levitz M (1968) Transport of amino acids by placenta. Am J Obstet Gynecol 101: 820-829

18. Szabo AJ, Grimaldi RD (1970) The effect of insulin on glucose metabolism of the incubated human placenta. Am J Obstet Gynecol 106: 75-78

19. Demers CM, Gabbe SG, Villee CA, Greep RO (1972) The effects of insulin on human placental glycogenesis. Endocrinology 91: $270-275$

20. Steel RB, Mosley JD, Smith CH (1979) Insulin and placenta: Degradation and stabilization, binding to microvillous membrane receptors, and amino acid uptake. Am J Obstet Gynecol 135: 522-529

21. Battaglia FC, Meschia G, Blechner J, Barron DH (1961) Effect of insulin and poisons and glucose uptake of sheep and goat placenta. Am J Physiol 200: 64-66

22. Paxon CL, Morris FH Jr., Adcock EW III (1978) Effect of uterine artery insulin infusions on umbilical glucose uptake in sheep. Pediatr Res 12: 864-867

23. Crandail SS, Palma PA, Morris FH Jr (1982) Effect of maternal serum insulin on umbilical extraction of glucose and lactate in fed and fasted sheep. Am J Obstet Gynecol 142: 219-224

24. Hay WW Jr, Sparks JW, Gilbert M, Battaglia FC, Meschia G (1984) Effect of insulin on glucose uptake by the maternal hindlimb and uterus, and by the fetus in conscious pregnant sheep. $\mathrm{J}$ Endocrinol 100: 119-124

25. Sybulsky S, Maughan GB (1971) Use of streptozotocin as diabetic agent in pregnant rats. Endocrinology 89: 1537-1540

26. Kervran A, Guillaume M, Jost A (1978) The endocrine pancreas of the fetus from diabetic pregnant rats. Diabetologia 15: 387-393 
27. Barash V, Gutman A, Shafrir E (1983) Mechanism of placental glycogen deposition in diabetes in the rat. Diabetologia 24: 63-68

28. Lasunción MA, Testar X, Palacin M, Chieri R, Herrera E (1983) Method for the study of metabolite transfer from rat mother to fetus. Biol Neonate 44: 85-92

29. Heding LE (1972) Determination of total serum insulin in insulintreated diabetic patients. Diabetologia 8:260-266

30. Somogyi M (1945) Determination of blood sugar. J Biol Chem 160: $69-73$

31. Huggett ASG, Nixon DA (1957) Use of glucose oxidase, peroxidase, and $\mathrm{O}$-dianisidine in determination of blood and urinary glucose. Lancet 1: 368-370

32. Zorzano A, Herrera E (1984) Liver and kidney cortex gluconeogenesis from L-alanine in fed and starved rats. Int J Biochem 16: 262-267

33. Good CA, Kramer H, Somogyi M (1933) The determination of glycogen. J Biol Chem 100: 485-491

34. Palacin M, Lasunción MA, Herrera E (1983) Transfer from mother to foetus of L-alanine and glycerol in fed and $48 \mathrm{hr}$-starved pregnant rats. Biochem Soc Trans 11: 731-732

35. Owens PC, Brinsmead MW, Waters J, Thorburn GD (1980) Ontogenic changes in multiplication-stimulating binding to tissues and serum somatomedin-like receptor activity in the ovine fetus. Biochem Biophys Res Commun 96:1812-1820

36. Nelson DM, Smith RM, Jarrett L (1978) Nonuniform distribution and grouping of insulin receptors on the surface of human placental syncytial trophoblast. Diabetes 27:530-538
37. Holzman IR, Philipps AF, Battaglia FC (1979) Glucose metabolism, lactate and ammonia production by the human placenta in vitro. Pediatr Res 13: 117-120

38. Diamant YZ, Shafrir E (1978) Placental enzymes of glycolysis, gluconeogenesis and lipogenesis in the diabetic rat and in starvation. Diabetologia 15: 481-485

39. Herrera E, Palacin M, Martin A, Lasunción MA (1985) Relationship between maternal and fetal fuels and placental glucose transfer in the rat with maternal diabetes of varying severity. Diabetes 34 (Suppl 2): $42-46$

40. Goodner CJ, Conway MJ, Werrbach JH (1969) Relation between plasma glucose levels of mother and fetus during maternal hyperglycemia, hypoglycemia, and fasting in the rat. Pediatr Res 3: 121-127

Received: 28 January 1985

and in revised form: 19 June 1985

Professor Emilio Herrera

Departamento de Investigación

Centro Ramón y Cajal

Crtra. Colmenar, Km 9

E-28034-Madrid

Spain 